\title{
Proposed method of well-child care in a resident's clinic
}

\author{
CARL R. BACKES, DO \\ ROBERT W. HOSTOFFER, DO \\ GARY L. OSBORN, DO \\ CAROLYN P. PRATER, DO \\ JOHN R. WALKER, DO
}

Uniformity in a teaching hospital's pediatric outpatient clinic is often inconsistent because of the varying numbers of housestaff involved in patient evaluation. We have developed a flow sheet that defines the appropriate standards of care to be delivered at the Doctors Hospital Pediatric Outpatient Clinic. This flow sheet encompasses a method of rapid assessment of growth, development, physical examination, immunization status, screening laboratory testing, and parental education. We have defined these parameters as the minimal evaluation to be completed at each preschool well-child visit.

The osteopathic philosophy emphasizes the integrated evaluation of body structure and function. In keeping with these ideals, we have reevaluated our pediatric outpatient clinic well-child care program. We found no standard protocol for delivery of preventive healthcare or maintenance. This problem was exacerbated by the rotating fashion in which attending and housestaff participated in the clinic. The need for a simple, but thorough, method of defining the standard of care was evident. We have implemented, and here propose, a chart design and flow sheet that guides the osteopathic physician through each well-child visit during the preschool years.

\section{Method}

The format of the charts was reorganized to a twopage flow sheet (Fig 1) containing assessments of growth, development, physical examination, immunization status, screening laboratory testing, and parental education to be completed at each scheduled well-child visit. Copies of the birth records are placed in the chart, and so noted on the flow sheet. The mother's preference regarding bottle- or breast-feeding is recorded on the flow sheet. Progress notes for sick-child visits, a telephone call log, growth chart, and immunization record complete the chart.

We have scheduled well-child visits at 2 weeks; $2,4,6,9,12,15$, and 18 months; and at 2, 3, and 4 years of age. These intervals are in accordance with the current guidelines for immunizations, ${ }^{1}$ and screening laboratory testing. ${ }^{2}$

Growth is assessed with serial measurements of height (length) and weight at each visit. Serial head circumference measurements are recorded up to 15 months. These data are plotted on a standard growth curve. Blood pressure (BP) screening starts at age 1 year, with the BP being measured in all four extremities at that time. Routine BP determinations are then made on an annual basis. ${ }^{3}$

Developmental assessment was extrapolated from the Denver Development Screening Test (DDST) ${ }^{4}$ Pertinent items were selected from each sector: personal-social, fine motor-adaptive, language, and gross motor. One item was chosen from each sector that fell at approximately the 75th to 90 th percentile rank. In our opinion, failure to meet these milestones indicates the need for further evaluation by completion of a formal DDST. Further workup or referral is based on these results.

At each well-child visit, a systematic physical examination includes assessment of vital signs and head/eyes/ears/nose/throat (HEENT), pulmonary, cardiac, abdominal, neurologic, dermatologic, genitourinary, and osteopathic examinations. Special emphasis is placed on specific systems at various 


\section{PE/ASSESSMENT}

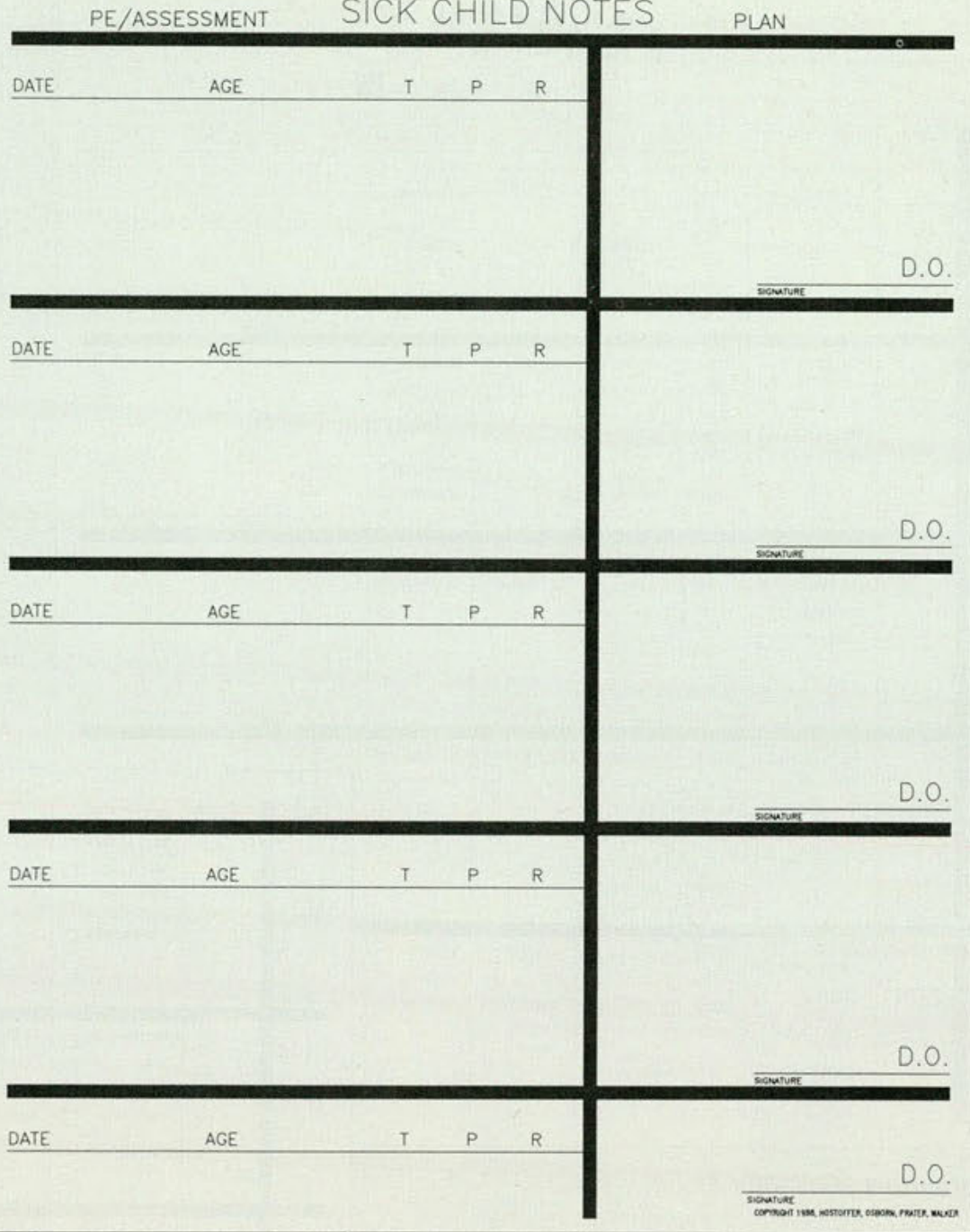

Figure 2. Sample sick-child progress notes.

Figure 3. Sample immunization record.

DOCTORS HOSPITAL PEDIATRIC CLINIC IMMUNIZATION RECORD
DPT
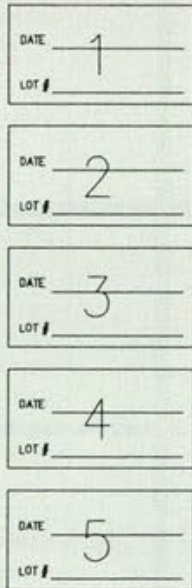

TOPV

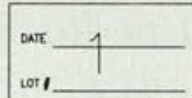

MMR

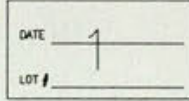

cort 2

ant 7

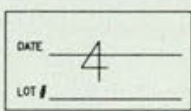

TB TINE

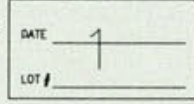

ProHibit

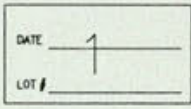

wert 2 


\section{Table}

Parent Education Packets

- Packet 1 at 2-week visit

Immunization information

Procedure for taking child's temperature

Infant bathing

Normal development

Infantile colic

Pedialyte

Diaper dermatitis

Sleeping habits

Feeding techniques: breast/bottle

Acetaminophen coupons

- Packet 2 at 4-month visit

Development

Nutrition: juices and cereal

Pedialyte

- Packet 3 at 6-month visit

Normal development

T.I.P.P.'s (American Academy of Pediatrics)

Poison control information

Mr. Yuk stickers

Ipecac dosage schedule

Nutrition: solid food

- Packet 4 at 12 -month visit

Nutrition

Development

Household safety

ProHibit ${ }^{\star}$ information

Guidelines for babysitter selection

- Packet 5 at 18-month visit

Nutrition

Development

Toilet training

TV viewing habits

Preschool selection

Dental hygiene

Discipline techniques

visits to screen for common abnormalities (eg, at 4 months, checking femoral pulses, hips, and feet for developmental anomalies).

Immunizations are administered according to the schedule recommended by the Advisory Committee on Public Health Services. ${ }^{1}$ We have updated this schedule to include the conjugated Haemophilus influenzae type $\mathrm{b}$ vaccine at 18 months of age. ${ }^{5}$

Screening laboratory testing is performed in accordance with the guidelines of the American Academy of Pediatrics. ${ }^{2}$ In our at-risk patient population, we have included screening for glucose-6phosphate dehydrogenase deficiency and sicklecell anemia at 9 months. The sickle-cell screening may be performed in the neonatal period by modified hemoglobin electrophoresis. ${ }^{6}$ A tuberculosis
(TB) tine test is administered at 1 and at 4 years of age. The preschool TB testing is often required for school admission. Screening urinalysis is completed at 6 and at 24 months as a simple renal and metabolic assessment. Ohio guidelines suggest screening for lead intoxication and iron-deficiency anemia by obtaining serial free erythrocytic protoporphyrin (FEP) levels at 9 and at 15 months, and at 2,3 , and 4 years of age. ${ }^{7}$

Because ethnic traditions and misconceptions abound in our patient population, we emphasize parent education in our pediatric clinic. Specially designed educational packets are distributed at the 2 -week and at the 4-, 6-, 12-, and 18-month visits. Included are pertinent booklets, brochures, and coupons appropriate for that well-child visit (Table). Formal hearing and vision testing is performed at age 4 years, prior to the beginning of school. ${ }^{2} \mathrm{Ap}$ propriate dental referrals are made at 3 years and annually thereafter. ${ }^{8}$

Any abnormality observed in the primary assessment of growth, development, and physical examination is fully documented in the sick-child progress notes (Fig 2). The resident devises an appropriate treatment plan and enters it in the progress notes.

A log of all physician-patient telephone calls is maintained in the chart. This is facilitated by the distribution of specifically designed note pads to each resident on call. These residents record each telephone call on these pocket notepads as the conversation is taking place, and the clinic nurses chart the documentation in the morning.

A separate immunization record (Fig 3 ) is placed on the jacket of each chart. The date of administration and manufacturer's lot number of all vaccines are recorded here.

To facilitate timely patient care, we have compiled a separate nursing flow sheet (Fig 4). This flow sheet enables the clinic nursing staff to anticipate the specific objectives of each well-child visit. This minimizes delays in the clinic.

\section{Discussion}

Our flow sheet defines a standard of care to be followed at each well-child visit at the Doctors Hospital Pediatric Clinic. This system not only allows rotating housestaff to deliver consistent care, but it also serves as an excellent teaching tool that emphasizes the importance of thorough and complete well-child health maintenance. One can readily adapt the format to a standard office computer system and easily make changes in the current recommendations for vaccination, education, or other 


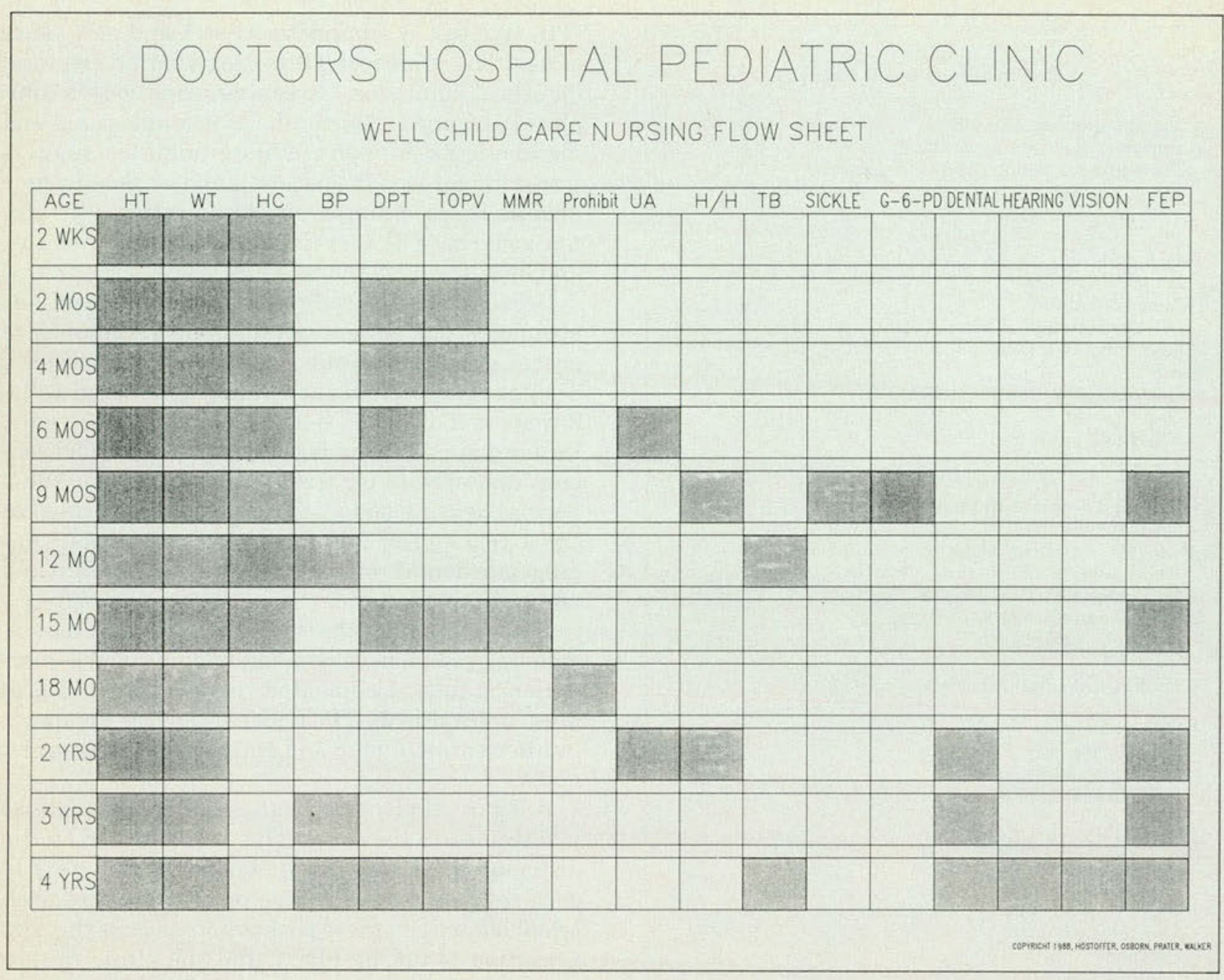

Figure 4. Nursing flow sheet.

variables. The office management software supplies the ability to automatically generate timely reminder letters to parents, informing them of approaching well-child visits. We feel this format meets our needs at the Doctors Hospital Pediatric Clinic and may be easily adapted to other clinic or office situations.

\footnotetext{
1. Katz SL: Controversies in immunization. Pediatr Infect Dis $J$ 1987;6:607-613.

2. Committee on Practice and Ambulatory Medicine, American Academy of Pediatrics: Recommendations for preventive pediatric health care. Pediatrics 1988;81:466.

3. Task Force on Blood Pressure Control in Children: Report of the Second Task Force on Blood Pressure Control in Children-1987. Pediat. rics 1987;79:1-25.

4. Frankenburg WK, Dodda JB, Kazuk E, et al: Denver Developmental Screening Test Manual, revised. Denver, University of Colorado Medical Center, 1975

5. Nelson JD, McCracken GH: New Haemophilus vaccine. Pediatric Infectious Disease Newsletter 1988;14:3-4.
}

6. National Health Institute Consensus: Newborn screening for sickle- cell disease and other hemoglobinopathies. NIH Consensus Development Conference Statement, 1987:6:1-8.

7. United States Department of Health and Human Services: Preventing Lead Poisoning in Young Children. Atlanta, Centers for Disease Control, 1985.

8. Herrmann HJ, Roberts MS: Preventive dental care: The role of the pediatrician. Pediatrics $1987 ; 80 ; 107-110$.

We wish to thank Ohio University College of Osteopathic Medicine for funding the grant that purchased the computer system on which we designed our format.

This program for well-child care was developed on the Convergent Technologies minicomputer, with desktop publishing and office management software supplied by Text \& Data Technologies Office Automation.

From Doctors Hospital Pediatric Clinic, Columbus, Ohio, and Ohio University College of Osteopathic Medicine, Athens, Ohio.

Reprint requests to Dr Prater, 4736 W. Esplanade, Metairie, LA 70006 . 
The \#1 prescribed allergy the U.S. and worldwide in the U.S. and world

\section{RAPID,}

UNSURPASSED RELIEF

Relief starts fast - most hay fever patients experience significant relief within 1 hour $^{1+}$

Relief peaks fast - within 3-4 hours ${ }^{2 * *}$

Relief is unsurpassed - proven in 30 double-blind clinical studies ${ }^{3-7}$

Relief is convenient - for high patient compliance ${ }^{\dagger \dagger}$

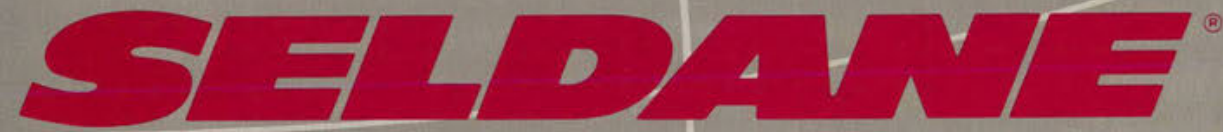

(terfenadine) 60 mg tablets BID

for seasonal allergic rhinitis

The ideal profile for fast, on-the-job relief

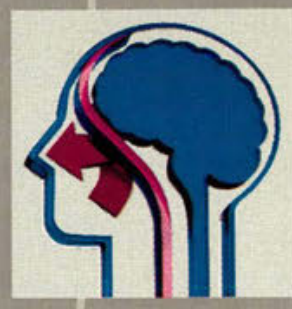

Based upon worldwide prescription and distribution information (1986-1988)-data on file

In most hay fever patients (55\%)

* In studies using the histamine-induced skin wheal test.

t + A summary of 26 studies relating compliance and dosage schedules of various types of medications

showed no significant difference in compliance rates between q.d. and b.i.d. dosing. There was significantly greater compliance with q.d. or b.i.d. dosing compared to t.i.d. or q.i.d. dosing $(p<0.05)$.

C. 1989, Merrell Dow Pharmaceuticals Inc.

Before prescribing Seldane, please see Brief Summary of Prescribing Information, which appears on the reverse side. 


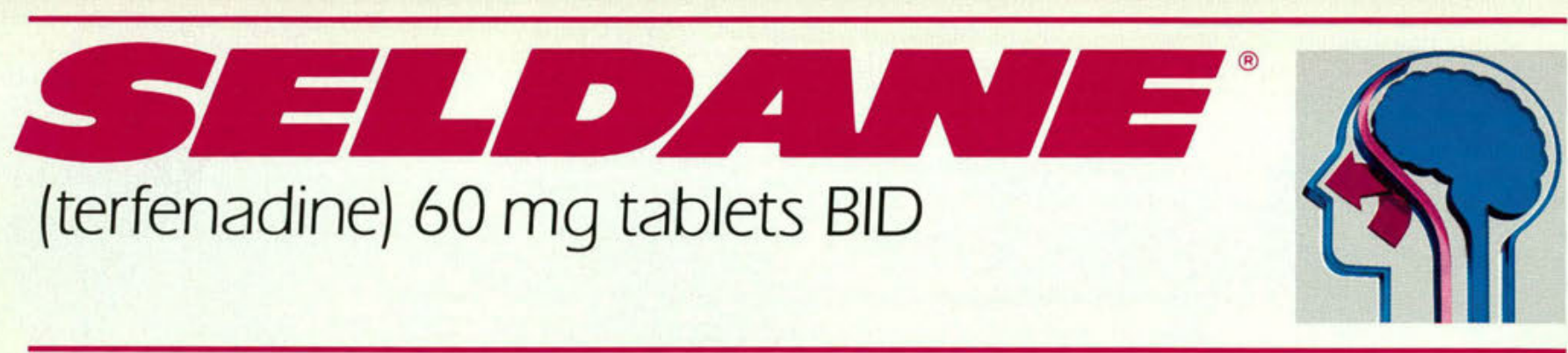

\section{- Fast, unsurpassed relief}

- Efficacy maintained in through-the-season use ${ }^{9-11}$ - Lets patients stay alert so they can perform at their best

\section{- B.i.d. dosing for high patient compliance}

\section{Seldane ${ }^{\circledR}$ (terfenadine) $60 \mathrm{mg}$ Tablets \\ BRIEF SUMMARY}

CAUTION: Federal law prohibits dispensing without prescription.

DESCRIPTION

Seldane (terfenadine) is available as tablets for oral administration. Each tablet contains $60 \mathrm{mg}$ terfenadine. Tablets also contain, as inactive ingredients: corn starch, gelatin, lactose, magnesium stearate, and sodium bicarbonate.

INDICATIONS AND USAGE

Seldane is indicated for the relief of symptoms associated with seasonal allergic minitis such as sneezing, rhinorrhea, pruritus, and lacrimation.

CONTRAINDICATIONS

Seldane is contraindicated in patients with a known hypersensitivity to terfenadine or any of its ingredients.

\section{PRECAUTIONS}

Information for patients

Patients taking Seldane should receive the following information and instructions. Antihistamines are prescribed to reduce allergic symptoms. Patients should be questioned about pregnancy or lactation before starting Seldane therapy, since the drug should be used in pregnancy or lactation only if the only as needed and not to exceed the prescribed dose. Patients should also be instructed to store this medication in a tightly closed container in a cool, dry place, away from heat or direct sunlight, and away medication in a children.

Carcinogenesis, mutagenesis, impairment of fertility

Carcinogenesis, mutagenesis, impairment of fertility Oral doses of terfenadine, corresponding to 63 times the recommended human daily dose, in mice for 18 months or in rats for 24 months, revealed no evidence of tumorigenicity

test assays with terfenadine have revealed no evidence of mutagenesis. Reproduction and fertility studies in rats showed no effects on male or female fertility at oral doses of up to 21 times the human daily dose. At 63 times the human daily dose there was a small but significant reduction in implants and at 125 times the human daily dose reduced implants and increased post-implantation losses were observed, which were judged to be secondary to maternal toxicity.

Pregnancy Category $C$

There was no evidence of animal teratogenicity. Reproduction studies have been performed in rats at doses 63 times and 125 times the human daily dose and have revealed decreased pup weight gain and survival when terfenadine was administered throughout pregnancy and lactation. There are no adequate and well-controlled studies in pregnant women. Seldane should be used during pregnancy only if the potential benefit justifies the potential risk to the fetus.

Nonteratogenic effects

Seldane is not recommended for nursing women. The drug has caused decreased pup weight gain and survival in rats given doses 63 times and 125 times the human daily dose throughout pregnancy and lactation. Effects on pups exposed to Seldane only during lactation are not known, and there are no adequate and well-controlled studies in women during lactation.

Pediatric use

Safety and effectiveness of Seldane in children below the age of 12 years have not been established.

General

Consideration should be given to potential anticholinergic (drying) effects in patients with lower airway disease, including asthma.

ADVERSE REACTIONS

Experience from clinical studies, including both controlled and uncontrolled studies involving more than 2,400 patients who received Seidane, provides information on adverse experience incidence for periods of a few days up to six months. The usual dose in these studies was $60 \mathrm{mg}$ twice daily, but in a small number of patients, the dose was as low as $20 \mathrm{mg}$ twice a day, or as high as $600 \mathrm{mg}$ daily.

In controlled clinical studies using the recommended dose of $60 \mathrm{mg}$ b.i.d., the incidence of reported adverse effects in patients receiving Seldane was similar to that reported in patients receiving placebo. (See Table below.)

\section{ADVERSE EVENTS REPORTED IN CLINICAL TRIALS}

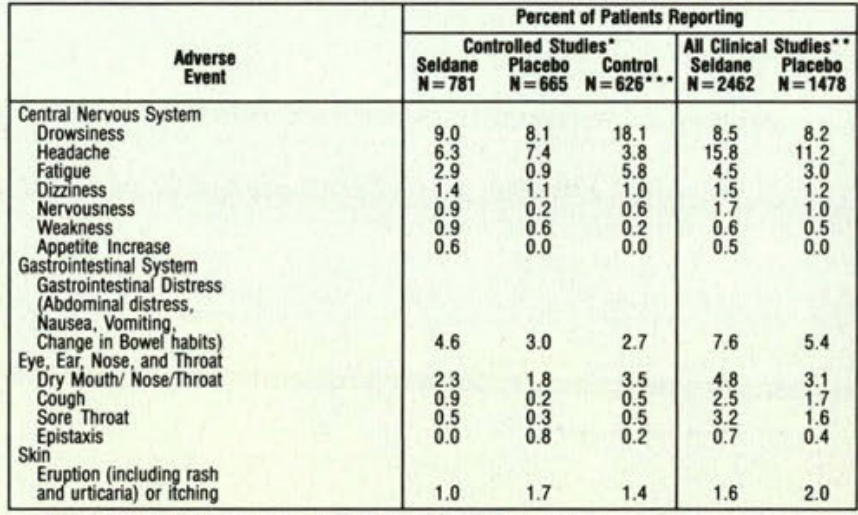

"Duration of treatment in "CONTROLLED STUDIES" was usually 7-14 DAYS
. Duration of treatment in "ALL CLINICAL STUDIES" was up to 6 months.

CONTROL DRUGS: Chlorpheniramine (291 patients), d-Chlorpheniramine (189 patients), Clemastine (146 patients)

In addition to the more frequent side effects reported in clinical trials (See Table), adverse effects have been reported at a lower incidence in clinical trials and/or spontaneously during marketing of Seldane that warrant listing as possibly associated with drug administration. These include: alopecia, (hair loss or thinning), anaphylaxis, angioedema, arrhythmia (including ventricular tachyarrhythmia), bronchospasm, confusion, depression, galactorrhea, hypotension, insomnia, menstrual disorders (including dysmenorrihea), musculoskeletal symptoms, nightmares, palpitation, paresthesia, photosensitivity, prolonged QT interval, seizures, sweating, syncope, tachycardia, tremor, urinary frequency, and visual disturbances. In clinical trials, several instances of mild, or in one case, moderate transaminase elevations were seen in patients receiving Seldane. Mild elevations were also seen in placebo treated in most cases available information is incomplete. In neither the clinical trials nor marketing experience is a causal relationship of liver abnormalities to Seldane use clear.

\section{OVERDOSAGE}

Information concerning possible overdosage and its treatment appears in Full Prescribing Information. DOSAGE AND ADMINISTRATION

The usual dosage for adults and children 12 years and older is $60 \mathrm{mg}$ (1 tablet) twice daily.

Product Information as of June, 1988

MERRELL DOW PHARMACEUTICALS INC.

Subsidiary of The Dow Chemical Company

Merrell Dow

PRINTED IN U.S.A.

References: 1. Murphy-O'Connor JC. Renton RL. Westlake DM: Comparative trial of two dose regimens of terfenadine in patients with hay fever. J Int Med Res 1984:12:333-337. 2. Hüther KJ. Renftle G. Barraud N. et al: Inhibitory activity of terfenadine on histamine-induced skin wheals in man. Eur J Clin Pharmacol 1977:12:195-199. 3. Kemp JP. Buckley CE. Gershwin ME, et al: Multicenter, double-blind, placebo-controlled trial of terfenadine in seasonal allergic rhinitis and conjunctivitis. Ann Allergy 1985:54:502-509.4. Backhouse Cl. Brewster BS, Lockhart JDF, et al: Terfenadine in allergic rhinitis. A comparative trial of a new

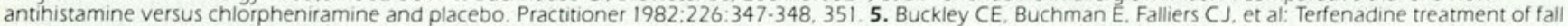

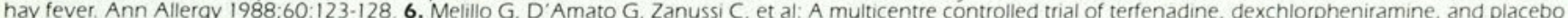

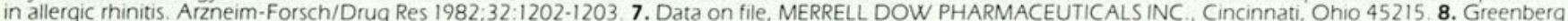
RN: Overview of patient compliance with medication dosing: a literature review. Clin Therapeutics 1984:6:592-599.9. Krause LB. Shuster S: The effect of terfenadine on dermographic wealing. Br J Dermatol 1984:10:73-79. 10. Kemp JP. Falliers CJ. Fox RW. et al: A multicenter, open study of the non-sedating

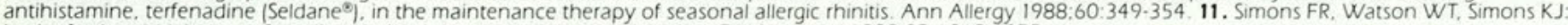
Lack of subsensitivity to terfenadine during long-term treatment. J Allergy Clin Immunol 1988:82:1068-1075. 